\title{
Optimization of a Lithium Ion Battery Bioleaching Process Utilizing Organic Acids Produced by Gluconobacter oxydans
}

David Vincent Gazzo, David W Reed July 2019

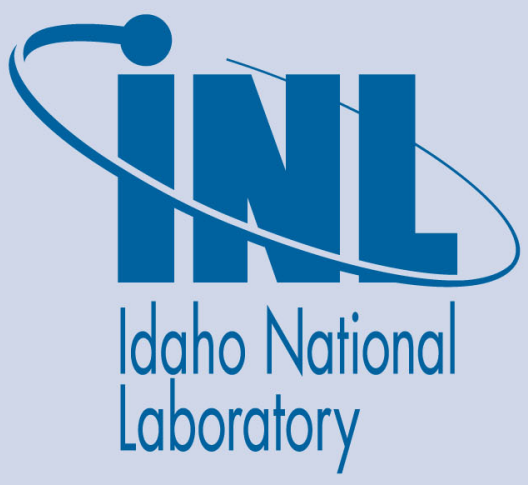

The INL is a U.S. Department of Energy National Laboratory operated by Battelle Energy Alliance 


\title{
Optimization of a Lithium lon Battery Bioleaching Process Utilizing Organic Acids Produced by Gluconobacter oxydans
}

\author{
David Vincent Gazzo, David W Reed
}

July 2019

Idaho National Laboratory Idaho Falls, Idaho 83415

http://www.inl.gov

Prepared for the U.S. Department of Energy

Office of Energy Efficiency and Renewable Energy Under DOE Idaho Operations Office Contract DE-AC07-05ID14517 


\title{
Optimization of a Lithium Ion Battery Bioleaching Process
}

\section{Utilizing Organic Acids Produced by Gluconobacter oxydans}

\author{
David Gazzo \\ Office of Science, Science Undergraduate Laboratory Internship Program \\ Montana State University, Bozeman, MT \\ Idaho National Laboratory, Idaho Falls, ID
}

July 2019

Prepared under the direction of David W. Reed in the Biological Science Department at Idaho National Laboratory. 


\section{TABLE OF CONTENTS}

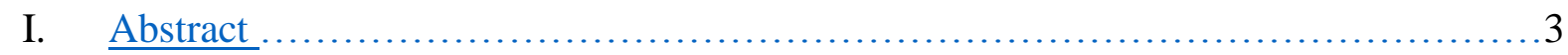

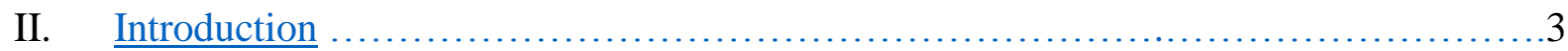

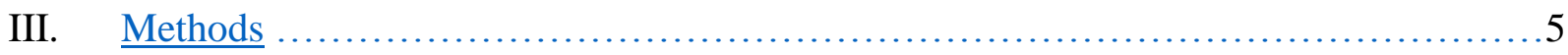

a. Modified Pikovskaya Phosphate Medium Preparation $\ldots . . . . \ldots \ldots \ldots \ldots \ldots . . . . . .5$

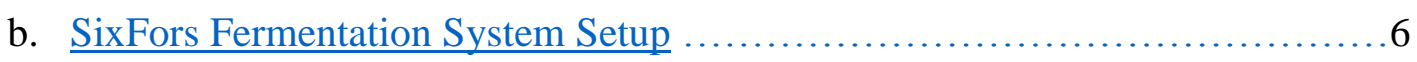

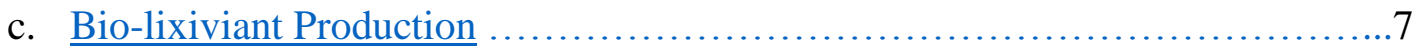

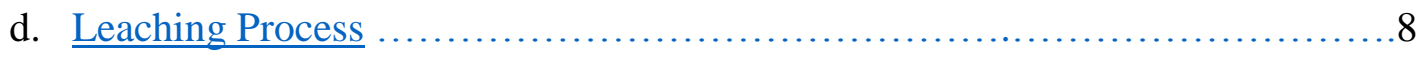

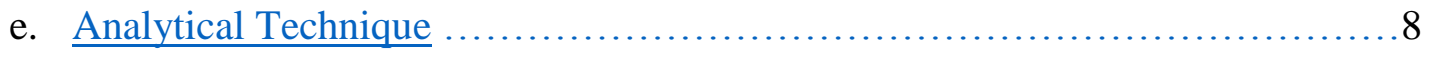

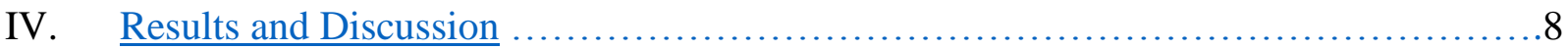

a. Bio-lixiviant Production on Various Amounts of Glucose $\ldots . . . \ldots \ldots \ldots \ldots \ldots . . . . . .8$

b. Leaching Performed on Lithium Ion Battery Cathode Powders ................... 10

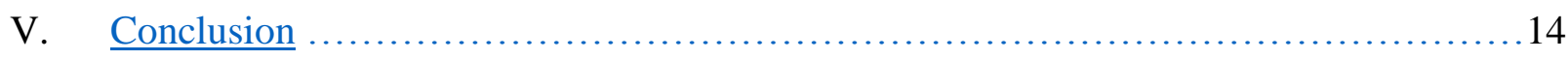

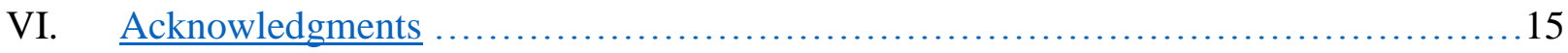

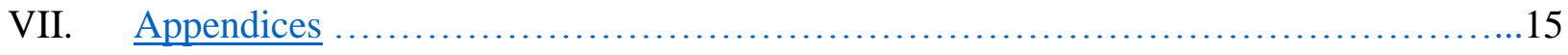

APPENDIX A: Corn Stover Hydrolysate Preparation........................... 15

APPENDIX B: Detailed Modified Pikovskaya Phosphate Medium Procedure ...... 16

APPENDIX C: Detailed Gluconobacter oxydans Initial Growth Procedure .......... 16

APPENDIX D: Detailed Gluconobacter oxydans Growth in the SixFors .............17

APPENDIX E: Detailed Bioleaching Table of Organization $\ldots \ldots \ldots \ldots \ldots \ldots \ldots \ldots . . .22$

APPENDIX F: Detailed Bioleaching Procedure and Analysis $. . . \ldots \ldots \ldots \ldots \ldots \ldots . . . .23$

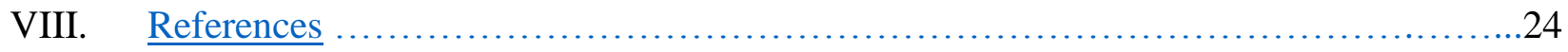




\section{ABSTRACT}

Growing our global economic and environmental focus relies, in part, on our development of a sustainable system to recycle valuable metals. Idaho National Laboratory (INL) has been working towards this goal through an organic avenue by utilizing bacterium. To succeed in this low-cost and environmentally safe practice, Gluconobacter oxydans has been employed for its ability to produce a biolixiviant known for its ability to leach valuable metals from end-of-life consumer products or industrial wastes. G. oxydans is a rod-shaped, gram negative, acidophilic, and obligately aerobic organism. Because of its advantageous metabolic pathways, it was grown in a batch reactor setting to produce sufficient amounts of a low-pH bio-lixiviant so that leaching processes could be optimized. Following the biolixiviant production, various leaching experiments were conducted. These included adding different molar ratios of a redox agent $\left(\mathrm{FeSO}_{4}\right)$ to the bio-lixiviant, varying concentrations of lithium ion battery cathode powders $\left(\mathrm{LiCoO}_{2}\right)$, varying leaching time, and varying the temperature each leaching was performed at. The bio-lixiviant succeeded in retrieving, on average, $90 \%$ of the cobalt. If this strategy were to be scaledup it would be a potential method to recycle critical materials from larger appliances such as electric vehicle batteries in an environmentally safe and economically profitable way.

\section{INTRODUCTION}

A number of critical elements are becoming more widely used in today's world for a multitude of devices that contribute to our growing movement towards a greener world. These appliances include wind turbines, permanent magnets, rechargeable batteries, and hybrid/electric cars along with many other applications. However, the predominate source of valuable materials and rare earth elements are not mined in the United States, and in the near future this could create an unsustainable situation resulting in insufficient amounts of critical materials for many appliances used in our society. ${ }^{[1]}$

To mitigate this supply risk and to increase the available amount of these valuable materials, recycling is essential. These metals can be extracted from waste streams and/or from products that utilize them but have reached the end of their lives. Currently, in the United States, the metal 
extraction methods being implemented are predominantly pyrometallurgical and hydrometallurgical. While affective, these methods can have a strong negative impact on the environment due to the hazardous wastes that they can create and are rarely profitable. $\frac{[10]}{[1}$

One such effective method utilizes inorganic acids, like hydrochloric $(\mathrm{HCl})$ or sulfuric acid $\left(\mathrm{H}_{2} \mathrm{SO}_{4}\right)$, to extract metals from various feedstocks. With efficiencies that can reach over $80 \%$, these methods are popular but pose a large environmental threat. ${ }^{[4]}$ However, it has been shown that organic acids can also have comparably high efficiencies to inorganic acids but with a smaller negative environmental impact and economically be more profitable. ${ }^{[8]}$ In this case bioleaching can be utilized, which is a form of biohydrometallurgy. Biohydrometallurgy is a process that utilizes microorganisms and their ability to produce organic or inorganic products. In this case organic acids can be synthesized and used to leach critical materials from a desired source in an environmentally healthy way. ${ }^{[2]}$

In this study, cobalt was leached from lithium ion battery cathode powders. Past studies have shown that gluconic acid can be utilized for this leaching process and Gluconobacter oxydans has also shown to predominantly produce gluconic acid as a byproduct because unlike many other aerobic microorganisms, it does not completely oxidize its carbon sources to water and carbon dioxide. Instead it incompletely oxidizes its substrates to aldehydes, ketones and organic acids. ${ }^{[7,8]}$ Because of this it was utilized for these experiments. To grow G. oxydans on pure glucose is, however, costly. A recent techno-economic analysis of bioleaching of rare earth elements from spent fluidized catalytic cracking catalyst using bio-lixiviant produced by G. oxydans from glucose estimated that $44 \%$ of the overall process expenses are due to the substrate requirements and of that, $98 \%$ of it was attributed to the cost of refined glucose. To mitigate and lower these costs other sources of glucose have been considered. Crain-Zamora et al. have shown that corn stover can be 
successfully used to provide G. oxydans with a sufficient amount of glucose for growth and production of the desired bio-lixiviant. $\stackrel{[3,10]}{ }$

To continue optimizing the leaching process to decrease the recovery costs of cobalt from lithium ion battery powders, various other factors were evaluated to test their effect on the leaching capabilities of the bio-lixiviant. These factors included different added molar amounts of a redox agent, varying leaching time and temperature it was performed at, and varying the concentration of the lithium ion battery cathode powders. The resulting outcomes were then used to identify the most efficient combination of conditions.

It was hypothesized that G. oxydans would be successful in producing a bio-lixiviant that could reliably leach the cobalt from lithium ion battery cathode powders in an environmentally heathy and economically profitable way.

\section{METHODS}

a. Modified Pikovskaya phosphate medium preparation:

The G. oxydans was grown in modified Pikovskaya phosphate medium (Pkm), as described by

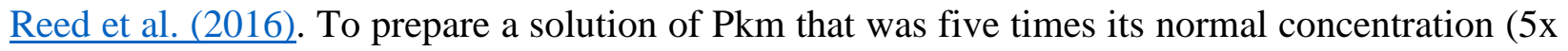
$\mathrm{Pkm}$ ), all of the components in Table 1 were combined sequentially in $2 \mathrm{~L}$ of $\mathrm{npH}_{2} \mathrm{O}$ using sterile technique (final volume $2 \mathrm{~L}$ ). Glucose, however, was prepared separately and added not to the Pkm directly, but to the bioreactor vessels. To prepare the $50 \%$ glucose solution, $250 \mathrm{~g}$ of glucose was added incrementally to $325 \mathrm{~mL}$ of warm $\mathrm{npH}_{2} \mathrm{O}$. Once all of the glucose was dissolved, $\mathrm{npH}_{2} \mathrm{O}$ was added until the final volume of $500 \mathrm{~mL}$ was reached. After the solution had cooled it was then filtered twice $(0.2 \mu \mathrm{m}, \mathrm{PES})$. To dilute to $1 \mathrm{x} \mathrm{Pkm}, 2400 \mathrm{~mL}$ of $\mathrm{npH}_{2} \mathrm{O}$ was added to $600 \mathrm{~mL}$ of the 
5x Pkm or $100 \mathrm{~mL}$ of 5x Pkm was added to the bioreactor vessels which had a final working volume of $500 \mathrm{~mL}$.

Table 1: Pikovskaya's Modified Medium

\begin{tabular}{|c|c|c|c|}
\hline Order & Components & $\mathbf{g} / \mathbf{L}$ & $\underline{\mathbf{5 X}(\mathbf{2 L})}$ \\
\hline 1 & $\left(\mathrm{NH}_{4}\right)_{2} \mathrm{SO}_{4}$ & 0.5 & $5 \mathrm{~g}$ \\
\hline 2 & $\mathrm{MgSO}_{4} \times 7 \mathrm{H}_{2} \mathrm{O}$ & 0.1 & $1 \mathrm{~g}$ \\
\hline 3 & $\mathrm{MnSO}_{4} \times \mathrm{H}_{2} \mathrm{O}$ & $1 \mathrm{E}-04$ & $1 \mathrm{~mL}(1 \mathrm{mg} / \mathrm{mL})$ \\
\hline 4 & $\mathrm{FeSO}_{4} \times 2 \mathrm{H}_{2} \mathrm{O}$ & $1 \mathrm{E}-04$ & $1 \mathrm{~mL}(1 \mathrm{mg} / \mathrm{mL})$ \\
\hline 5 & $\mathrm{KCl}_{2}$ & 0.2 & $2 \mathrm{~g}$ \\
\hline 6 & $\mathrm{CaCl}_{2} \times 2 \mathrm{H}_{2} \mathrm{O}$ & 0.046 & $0.46 \mathrm{~g}$ \\
\hline 7 & $\mathrm{KH}_{2} \mathrm{PO}_{4}$ & 0.37 & $3.7 \mathrm{~g}$ \\
\hline 8 & Yeast Extract & 0.5 & $5 \mathrm{~g}$ \\
\hline 9 & Glucose & 40 & prepare separate \\
\hline
\end{tabular}

b. SixFors fermentation system setup:

Six separate batch reactors are controlled by the SixFors system. Temperature, air flow, stirring speed, and antifoam addition can all be manipulated and controlled. $\mathrm{pH}$ and dissolved oxygen (D.O.) content can also be controlled but were only monitored in this experiment. Before each bioreactor run, the $\mathrm{pH}$ and D.O. probe were autoclaved along with the rest of the vessel. Calibration of the $\mathrm{pH}$ probes were done with $\mathrm{pH}$ buffer solutions. D.O. probes were polarized overnight before they were calibrated by flowing air and nitrogen separately through the vessels to obtain low and high readings of oxygen. In this experiment the temperature was held at $30^{\circ} \mathrm{C}$, the stirring speed was set to $600 \mathrm{rpm}$, the air flow was held at $\sim 1.06 \mathrm{~L} / \mathrm{min}$, and no antifoaming solution was used. 
c. Bio-lixiviant production:

Gluconobacter oxydans was grown in the modified Pikovskaya phosphate medium (Pkm). ${ }^{[6]}$ The modification step included the replacement of calcium phosphate with $\mathrm{CaCl}_{2} \cdot 7 \mathrm{H}_{2} \mathrm{O}$ and $\mathrm{KH}_{2} \mathrm{PO}_{4}$. This was done so that the calcium and phosphate would fully dissolve into the aqueous medium for use in the SixFors fermentation system. ${ }^{[8]}$ Before inoculating the reactors, G. oxydans was grown separately in a shake flask until it reached exponential growth (O.D.600 $\mathrm{nm}$ of 0.25$0.75,1.9 \mathrm{E}+08-7.5 \mathrm{E}+08$ cells $/ \mathrm{mL}$ ). It was then isolated and added to a Pkm solution that contained no glucose so that further growth was halted. ${ }^{[5]}$ Small aliquots $(1 \mathrm{~mL})$ were also set aside for preservation by freezing, following the addition of $70 \%$ glycerol (final glycerol concentration $20 \%)$.

The media that was used for growth in the reactors contained $100 \mathrm{~mL}$ of 5x Pkm (no glucose present), $40 \mathrm{~mL}$ of a $50 \%$ glucose solution (final concentration $40 \mathrm{~g} / \mathrm{L}$ ), and $\mathrm{npH}_{2} \mathrm{O}$ was added until the final volume of $500 \mathrm{~mL}$ was reached (working volume of the SixFors reactors) in the reactors. The reactors were autoclaved prior to the glucose addition so that any contamination present in the solution would be eliminated and the glucose would not be caramelized. The $50 \%$ glucose stock was sterilized by filtering twice $(0.20 \mu \mathrm{m}$ PES $)$. After inoculation with the previously frozen $1 \mathrm{~mL}$ aliquots and the addition of glucose, the G. oxydans was incubated for 36-40 hours at $30^{\circ} \mathrm{C}$ and $600 \mathrm{rpm}$. To collect the bio-lixiviant, the solution was centrifuged at 6000 times gravity for 30 minutes and filtered $\left(0.20 \mu \mathrm{m}\right.$ PES). The final product was then kept refrigerated at $4^{\circ} \mathrm{C}$ until use in the bioleaching experiments. 


\section{d. Leaching process:}

A redox reagent $\left(\mathrm{FeSO}_{4}\right)$ was added to the bio-lixiviant in an equal molar amount to cobalt, leaching times were varied from 1.5 to 24 hours, temperatures were varied between $20^{\circ} \mathrm{C}$ and $70^{\circ} \mathrm{C}$, the concentration of the lithium ion battery cathode powders varied between $1.5 \%$ and $33 \%$, and different acids were used instead of the bio-lixiviant. ${ }^{[9]}$

\section{e. Analytical technique:}

The resulting leachate solutions were analyzed by a TXRF (Benchtop Total Feflection X-ray Fluorescence) spectrometer to determine REE concentrations. Samples were diluted (1:50) with $0.2 \%$ polyvinyl alcohol and a Selenium standard. These were then vortexed before $10 \mu \mathrm{L}$ were placed onto disposable acrylic disks and dried. Before analyzing, it was imperative that each samples height was checked before being added to the TXRF spectrometer. If the samples were not flush with the plate and contained any bubbles, new ones were platted and dried again (damage to the TXRF spectrometer can result from samples that are tall and able to scratch the device). The standard was used as a basis for determining the concentration cobalt. Each sample was then analyzed for a minimum of 1000 seconds.

\section{RESULTS AND DISCUSSION}

a. Bio-lixiviant production from various glucose concentrations:

Growth patterns for the cultures at each glucose concentration, based on absorbance readings done at $600 \mathrm{~nm}$, are is shown in FIG. 1. It is unknown why there are occasional sudden drops in cell density but the general decrease in cell density is believed to be due to the deceased bacterial cells being lysed. Determining a higher optimal concentration of glucose to grow G. oxydans on 
would result in higher concentrations of organic acids in the bio-lixiviant and could result in larger bioleaching efficiencies.

Gluconobacter oxydans grew well with 80, 100, and $150 \mathrm{~g} / \mathrm{L}$ glucose. When grown with 40 g/L glucose, acid concentrations ranged between 200 and $230 \mathrm{mM}$, however, with these increased concentrations of glucose, acid concentrations almost tripled. $635 \mathrm{mM}$ of acid was produced with $150 \mathrm{~g} / \mathrm{L}$ glucose. At glucose concentrations of 200, 250, and $300 \mathrm{~g} / \mathrm{L}$, little growth occurred though, and visible crystals formed in the medium. The $\mathrm{pH}$ still dropped to about 2.4 , however, acid concentrations did not increase, but instead decreased (Table 2).

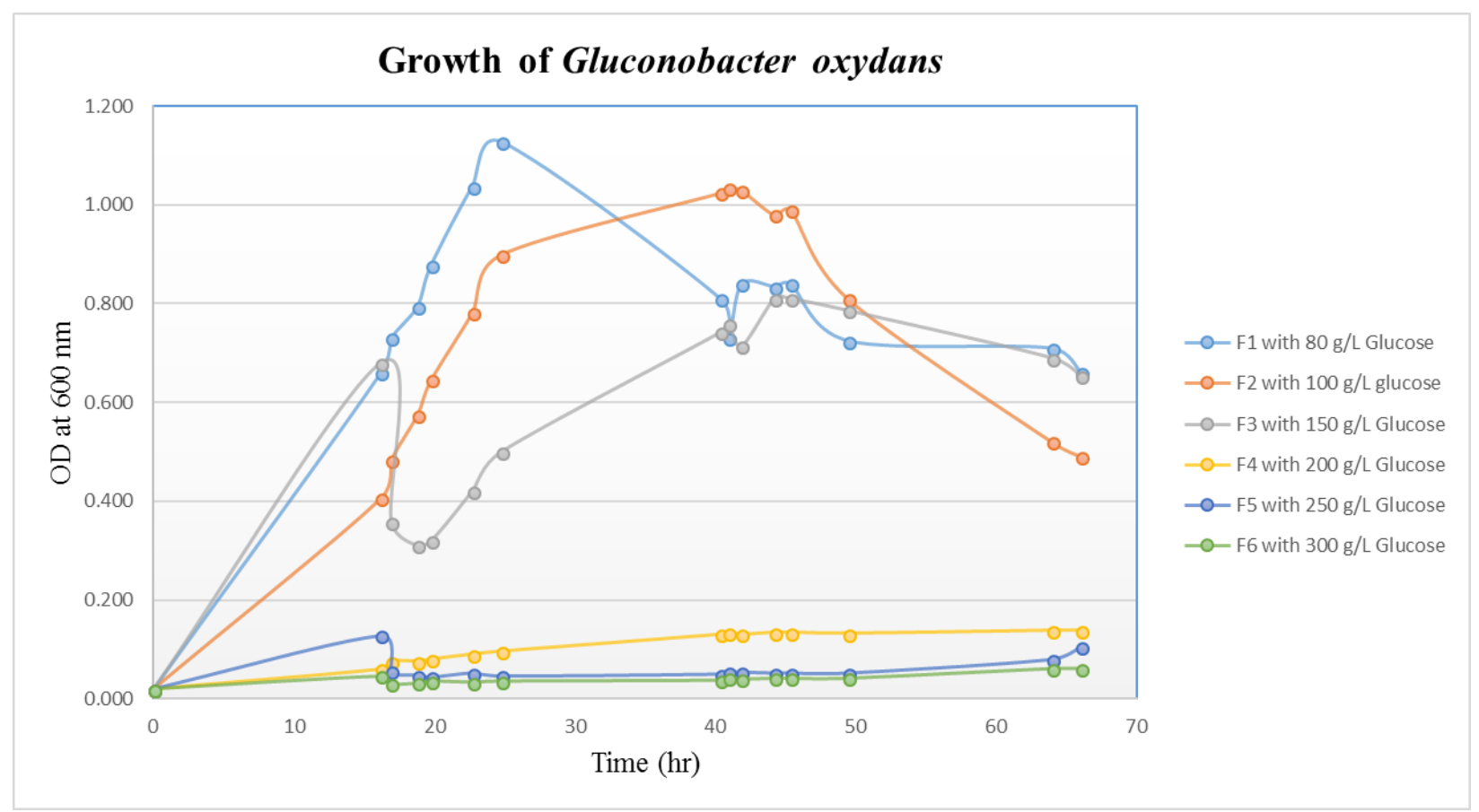

FIG. 1. Growth of G. oxydans on varying amounts of glucose 
Table 2: Resulting acid concentrations produced by G. oxydans in varying amounts of glucose

\begin{tabular}{|c|c|c|}
\hline $\begin{array}{c}\text { Initial Concentration of } \\
\text { Glucose }(\mathrm{g} / \mathrm{L})\end{array}$ & $\begin{array}{c}\text { Final Concentration } \\
(\mathrm{mM})\end{array}$ & Final $\mathrm{pH}$ \\
\hline 80 & 583.20 & 1.86 \\
\hline 100 & 589.97 & 1.87 \\
\hline 150 & 635.19 & 1.81 \\
\hline 200 & 237.80 & 1.96 \\
\hline 250 & 128.25 & 2.21 \\
\hline 300 & 84.08 & 2.35 \\
\hline
\end{tabular}

b. Leaching of lithium ion battery cathode powders:

By comparing with previous data from Dr. David W. Reed, it has been deduced that the addition of a redox agent, in this case $\mathrm{FeSO}_{4}$, greatly increased the amount of cobalt extracted from lithium ion battery cathode powder. Shown in FIG. 2, extraction percentages were increased from $15 \%$ to $83 \%$ when $\mathrm{FeSO}_{4}$ was present in the solution. During the leaching process the iron reduces $\mathrm{Co}^{3+}$ to $\mathrm{Co}^{2+}$. However, this oxidizes the iron from $\mathrm{Fe}^{2+}$ to $\mathrm{Fe}^{3+}$ which can precipitate out of solution if the $\mathrm{pH}$ of the solution is greater than 4 . The organic acid content of the bio-lixiviant, however, prevents this from happening. Along with the bio-lixiviant, sulfuric and gluconic acid were also tested to determine their efficiency in retrieving cobalt from $\mathrm{LiCoO}_{2}$. The retrieval of cobalt using the bio-lixiviant with the added redox agent increased the yield by $68 \%$. Adding the redox agent in a one to one molar ratio with the cobalt present in the cathode powder, greatly increased efficiency, but higher iron concentrations only increased the efficiency by about $5 \%$ (FIG. 2).

For a basis, a standard leach was performed for 24 hours with the bio-lixiviant at a temperature of $30^{\circ} \mathrm{C}$, agitated at $150 \mathrm{rpm}$, with $1.5 \%$ lithium ion cathode battery powder, and $260 \mathrm{mg}$ of $\mathrm{FeSO}_{4}$. 
In each experimental trial one factor was changed to determine its effect on leaching efficiencies. The amount of cobalt retrieved varied from $48 \%$ to $95 \%$ depending on how long the solution was incubated. The most efficient leach occurred when it was incubated for 18 hours. It resulted in an average $89 \%$ of cobalt being retrieved (FIG. 3).

To Determine the optimal temperature to perform the bioleaching, solutions were incubated at $20^{\circ} \mathrm{C}, 30^{\circ} \mathrm{C}, 50^{\circ} \mathrm{C}$, and $70^{\circ} \mathrm{C}$. The amount of cobalt extracted ranged from $78 \%$ to $99 \%$, however the variation between each temperature was not large. It is likely that the bio-leaching process will be more profitable at lower temperatures (FIG. 4).

At higher concentrations of the lithium ion battery cathode powder, cobalt retrieval efficiencies decreased. This is thought to occur because of the lack of access that the bio-lixiviant had to the solid matrix. The solid could not distribute evenly enough to allow the bio-lixiviant to facilitate the required reactions (FIG. 5).

Along with the bio-lixiviant ( $230 \mathrm{mM}, \mathrm{pH} \sim 2.10)$, sulfuric and gluconic acid were also tested to compare their leaching capabilities. Sulfuric acid was tested at a concentration of $220 \mathrm{mM}$ (pH of 0.95 ) and at a $\mathrm{pH}$ of 2.15 to determine what the effects would be at similar concentrations and $\mathrm{pH}$ 's to the bio-lixiviant. The gluconic acid was also tested since the bio-lixiviant is mainly composed of gluconic acid. It was at a concentration of $220 \mathrm{mM}$ and had $\mathrm{pH}$ of 2.17. The biolixiviant performed the best with an average percent retrieval of $83 \%$, while the gluconic acid 
retrieved $77 \%$ of cobalt on average, the sulfuric acid at $220 \mathrm{mM}$ retrieved $74 \%$, and the sulfuric acid at a $\mathrm{pH}$ of 2.15 retrieved $27.6 \%$ of the cobalt (FIG. 6).

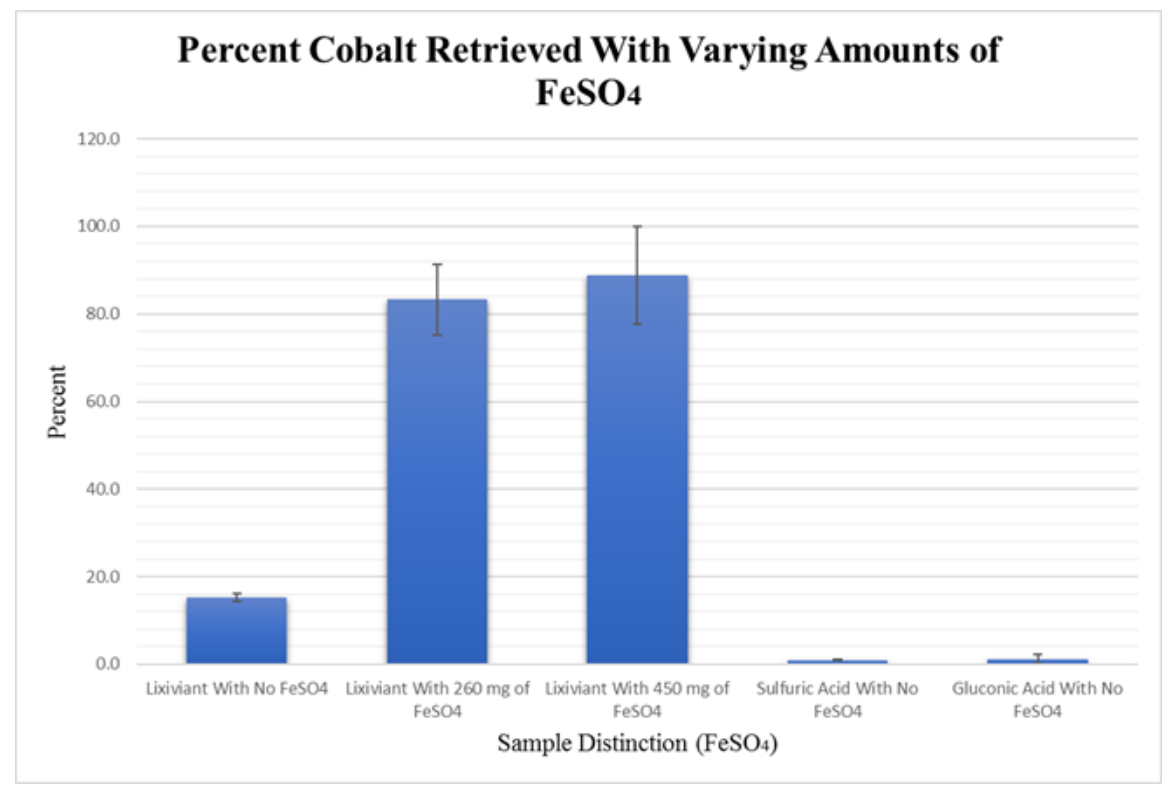

FIG. 2. Recovery of cobalt from solid $\mathrm{LiCOO}_{2}$ powder with different amounts of ferrous sulfate

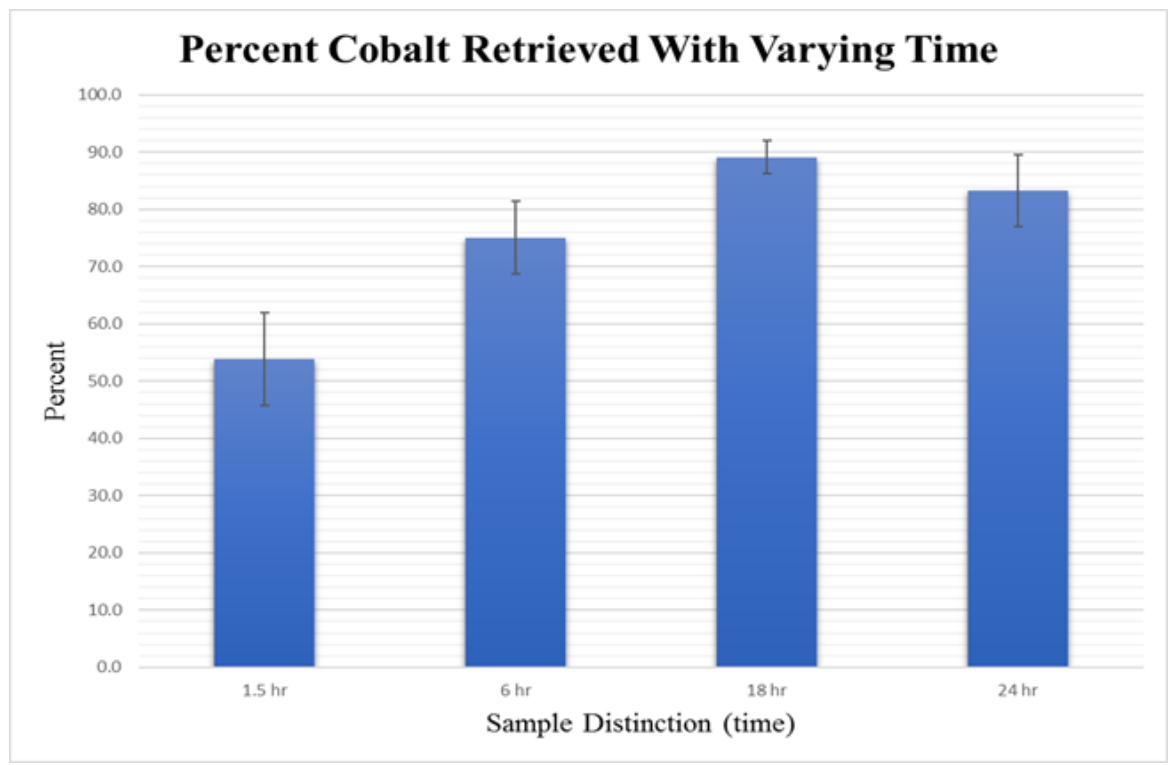

FIG. 3. Recovery of cobalt from solid $\mathrm{LiCoO}_{2}$ powder with different leaching times 


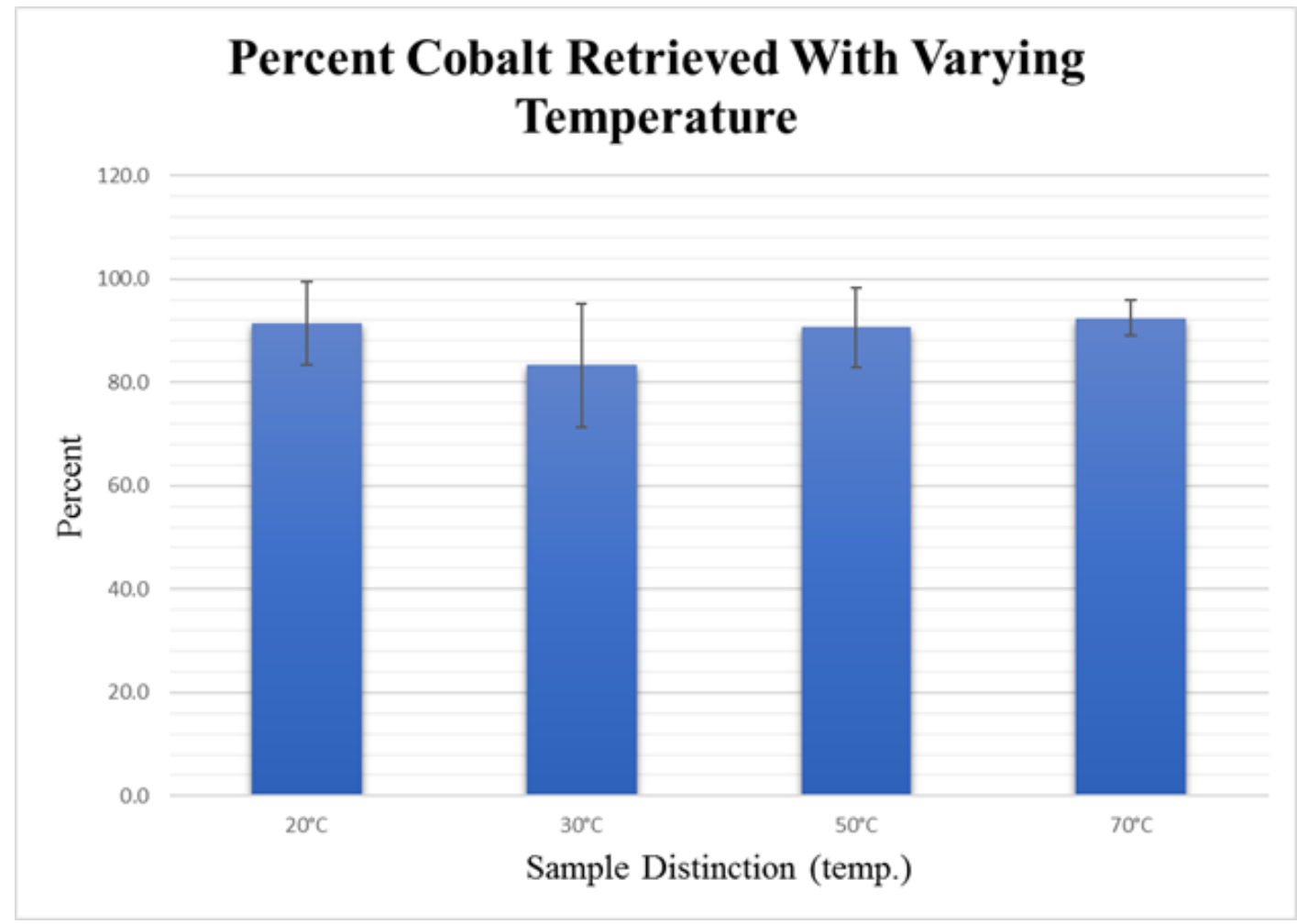

FIG. 4. Recovery of cobalt from solid $\mathrm{LiCOO}_{2}$ powder with different leaching temperatures

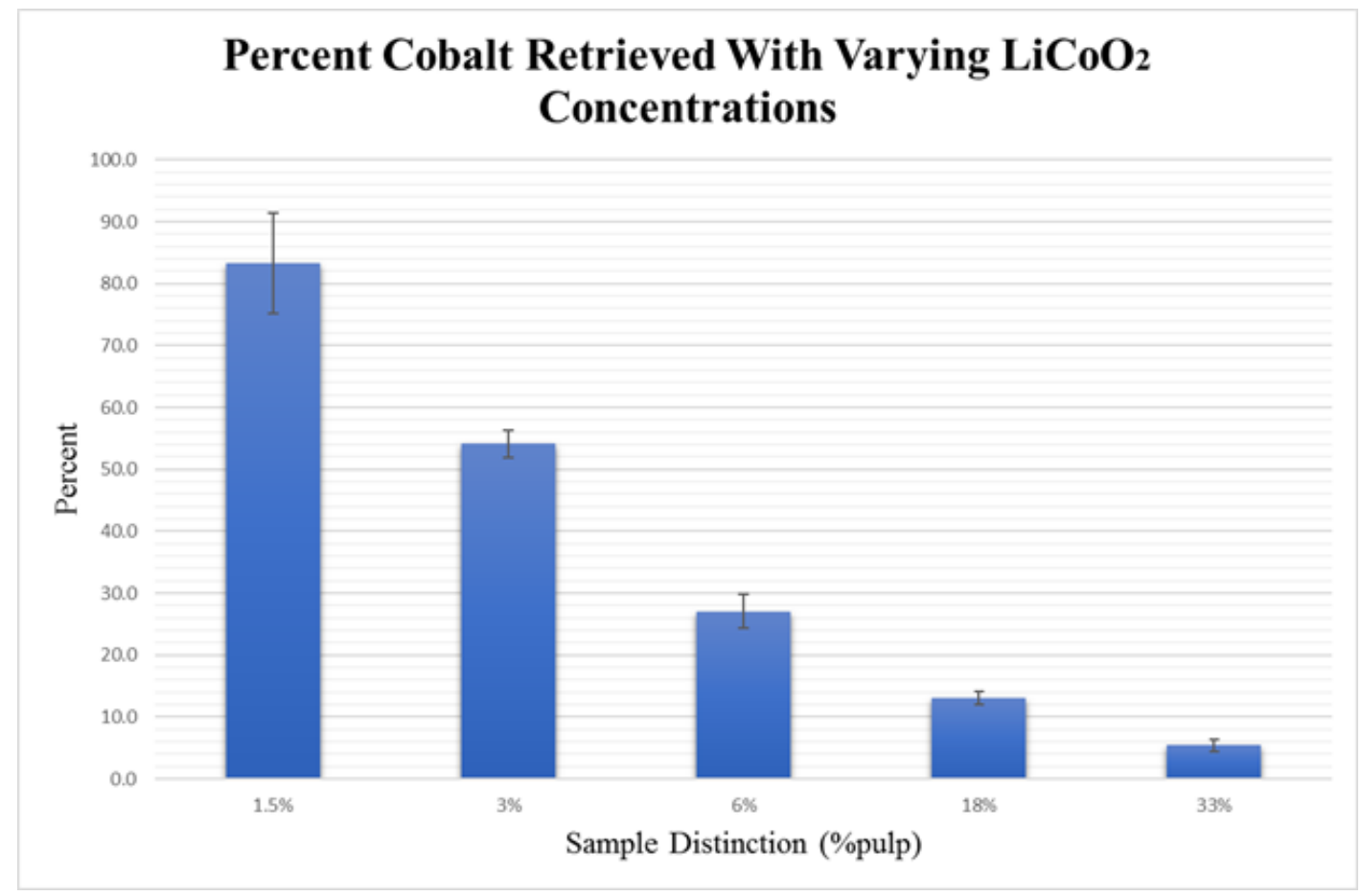

FIG. 5. Recovery of cobalt from solid $\mathrm{LiCOO}_{2}$ powder with different concentrations of $\mathrm{LiCoO}_{2}$ 


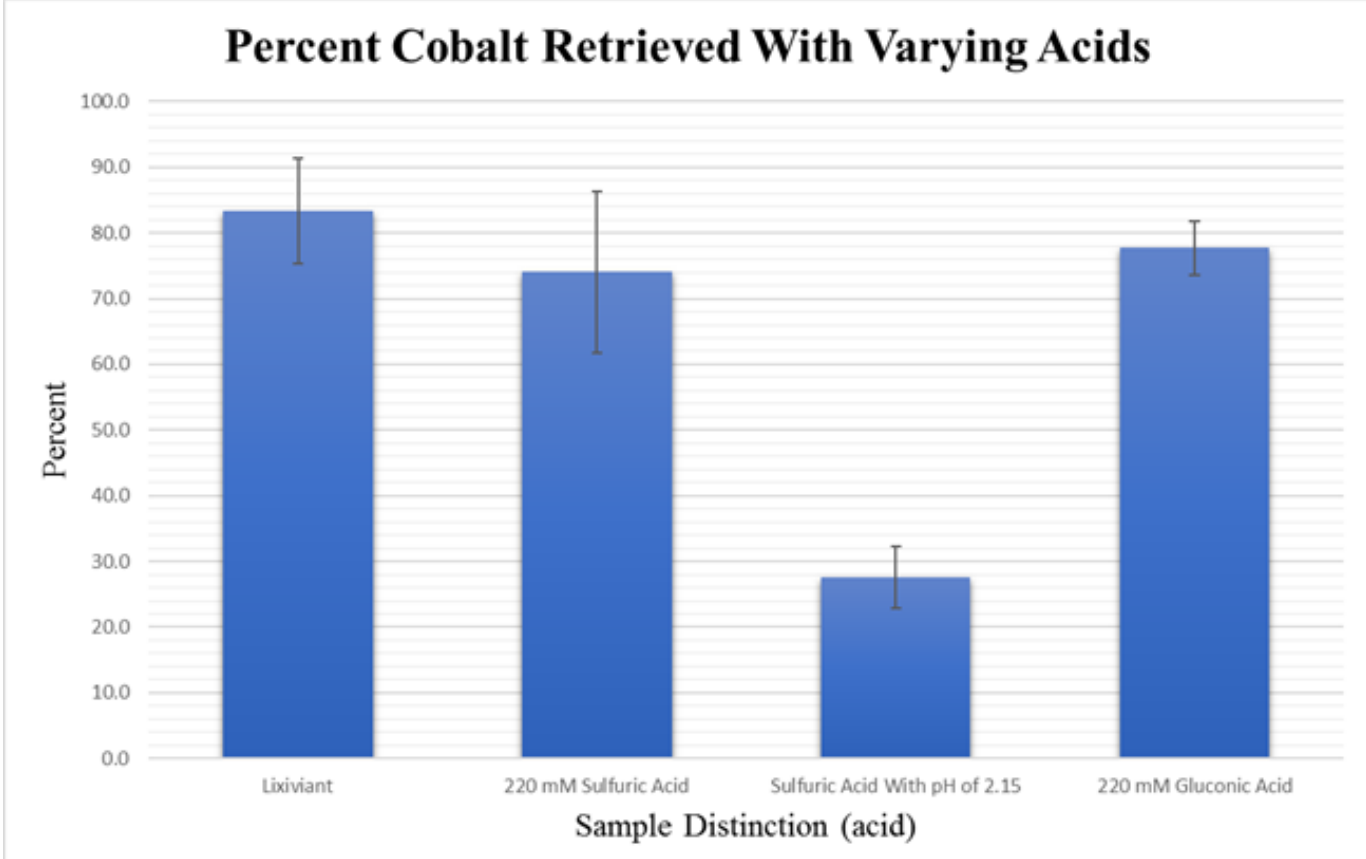

FIG. 6. Recovery of cobalt from solid $\mathrm{LiCOO}_{2}$ powder with different acids

\section{CONCLUSION}

By combining the most efficient processes, a potential optimized procedure was developed. Utilizing the bio-lixiviant and performing the leaching processes at $20^{\circ} \mathrm{C}$ for 18 hours with $1.5 \%$ lithium ion battery cathode powder and $260 \mathrm{mg}$ of ferrous sulfate, this procedure could be successful in retrieving the higher yield of cobalt form the battery cathode powder. However, this potential optimization still needs to be tested and is included in our future work. In addition to this, future work will also entail expanding this recycling process so that it can be scaled up to encompass other wastes such as electric vehicle batteries. 


\section{ACKNOWLEDGMENTS}

I'd like to acknowledge mentors Dr. David W. Reed, Dr. Vicki S. Thompson, and Dr. Yoshiko Fujita from the Idaho National Laboratory for their guidance and direction during my internship.

Thanks are also due to Dr. Kastli D. Schaller for analyzing many of my samples and to Mary E.

Case for her instructions in the use of the TXRF spectrometer; and I'd like to thank Katherine Scalzone for her guiding hand and advice throughout my internship. In addition, I'd like to thank CMI for funding the Lithium-ion battery project (through DOE Idaho Operations Office Contract DE-AC07-05ID14517) and Idaho National Laboratory for awarding me a position here.

\section{APPENDICES}

APPENDIX A: Corn Stover hydrolysate preparation

1. To make a $10 \%$ solution of corn stover for one reactor run with only three fermenters being used, a final volume of $1400 \mathrm{~mL}$ is desired (140 grams of dry corn stover)

2. Dry the corn stover in an incubator at $60^{\circ} \mathrm{C}$ overnight

a. Separate the corn stover into multiple beakers so that it can dry completely

3. Making $0.1 \mathrm{M}$ sodium acetate buffer

a. Prepare $0.1 \mathrm{M}$ acetic acid by mixing $2.88 \mathrm{~mL}$ of glacial acetic acid and $497.12 \mathrm{~mL}$ of $\mathrm{npH}_{2} \mathrm{O}$

b. Prepare $0.1 \mathrm{M}$ sodium acetate by mixing $6.8056 \mathrm{~g}$ of sodium acetate trihydrate and $500 \mathrm{~mL}$ of $\mathrm{npH}_{2} \mathrm{O}$

c. Now mix $413 \mathrm{~mL}$ of $0.1 \mathrm{M}$ sodium acetate and $287 \mathrm{~mL}$ of $0.1 \mathrm{M}$ acetic acid

i. $\mathrm{pH}$ needs to be 4.8 so adjust with acetic acid or sodium acetate as needed

4. Adding $0.1 \mathrm{M}$ sodium acetate buffer to dry corn stover

a. In two $2800 \mathrm{~mL}$ Erlenmeyer flasks (with screw tops) combine $70 \mathrm{~g}$ of dry corn stover and $350 \mathrm{~mL}$ of $0.1 \mathrm{M}$ sodium acetate buffer

5. To each flask add $1.358 \mathrm{~mL}$ of HTec 2 and $13.44 \mathrm{~mL}$ of CTec 2

a. These are Hemicellulase enzymes and will perform the hydrolysis of corn stover and release sugars

6. Adjust the volume to $700 \mathrm{~mL}$ with $\mathrm{npH}_{2} \mathrm{O}$

7. Incubate the solutions for five days at $50^{\circ} \mathrm{C}$ and $200 \mathrm{rpm}$

8. After incubation centrifuge the solutions

a. Centrifuge at 7000 times gravity for 30 minutes at $4{ }^{\circ} \mathrm{C}$

b. Do this four times

i. Transfer the supernatants to new $500 \mathrm{~mL}$ centrifuge bottles and rebalance them 
ii. Resuspend the pellets and dump them into the spent media tub

iii. Centrifuge bottles can be cleaned in the sink with soap

9. Sterilize the solution by filtration

a. Start with a pore size of $0.45 \mu \mathrm{m}$ to remove larger particles so that the smaller filters won't be quickly clogged

b. Then filter the solution with $0.2 \mu \mathrm{m}$ syringe filters using a $30 \mathrm{~mL}$ or $20 \mathrm{~mL}$ syringe

c. Finish with the $500 \mathrm{~mL} 0.2 \mu \mathrm{m}$ filters

d. Store the hydrolyzed corn stover in the refrigerator

10. To find the sugar concentrations make up dilutions to send out

a. Neutralize a small amount of the hydrolyzed corn stover solution to a $\mathrm{pH}$ of about 5.5-6.0 with calcium carbonate solid

b. After neutralization, filter the solution with a $0.2 \mu \mathrm{m}$ syringe filter

c. Obtain four $2 \mathrm{~mL}$ glass HPLC vials with $9 \mathrm{~mm}$ thread and pre-slit septa screw caps

i. Vial 1: undiluted

ii. Vial 2: 1 to 5 dilution

iii. Vial 3: 1 to 25 dilution

iv. Vial 4: 1 to 35 dilution

APPENDIX B: Detailed modified Pikovskaya phosphate medium procedure

1. In $2 \mathrm{~L}$ of $\mathrm{npH}_{2} \mathrm{O}$ combine $\mathrm{Pkm}$ ingredients sequentially

a. Add $5 \mathrm{~g}$ of $\left(\mathrm{NH}_{4}\right)_{2} \mathrm{SO}_{4}$

b. Add $1 \mathrm{~g}$ of $\mathrm{MgSO}_{4} \times 7 \mathrm{H}_{2} \mathrm{O}$

c. Add $1 \mathrm{~mL}$ of $\mathrm{MnSO}_{4} \times \mathrm{H}_{2} \mathrm{O}$ and $\mathrm{FeSO}_{4} \times 2 \mathrm{H}_{2} \mathrm{O}$

d. Add $2 \mathrm{~g}$ of $\mathrm{KCl}$

e. Add $0.46 \mathrm{~g}$ of $\mathrm{CaCl}_{2} \times 2 \mathrm{H}_{2} \mathrm{O}$

f. Add $3.7 \mathrm{~g}$ of $\mathrm{KH}_{2} \mathrm{PO}_{4}$

g. Add $5 \mathrm{~g}$ of yeas extract

2. Autoclave the solution for the required time on a liquid cycle

a. Let the solution cool after it's finished autoclaving

3. Adjust volume back to $2 \mathrm{~L}$

a. Do this in a graduated cylinder with autoclaved $\mathrm{npH}_{2} \mathrm{O}$

4. Transport this to two $1 \mathrm{~L}$ bottles

a. Store the 5x Pkm solution on the bench top out of the way

APPENDIX C: $\underline{\text { Detailed Gluconobacter oxydans initial growth procedure }}$

1. Obtain three $1 \mathrm{~L}$ flasks that are unbaffled

a. Add $350 \mathrm{~mL}$ of $1 \mathrm{x} \mathrm{Pkm}$ with glucose (final concentration of glucose is $10 \mathrm{~g} / \mathrm{L}$ )

i. For $350 \mathrm{~mL}$ of $\mathrm{Pkm}$ add about $7.5 \mathrm{~mL}$ of $50 \%$ glucose solution

2. Incubate for 29 hours at $30^{\circ} \mathrm{C}$ and $150 \mathrm{rpm}$ 
a. Check that the flasks fit in the incubator

3. Check O.D. (absorption) at $\underline{600 \mathrm{~nm}}$

a. Should be between 0.25 and 0.75

b. Clean the cuvettes after use

4. Transfer to separate $500 \mathrm{~mL}$ centrifuge bottles

a. If temperature can be controlled place the range to $6^{\circ} \mathrm{C}-8^{\circ} \mathrm{C}$

b. Spin at 6000 times gravity for 20 minutes

c. Pour off excess once finished

5. Wash with $30 \mathrm{~mL}$ of Pkm that contains no glucose

a. Add Pkm to centrifuge bottles and vortex to resuspend

b. Spin at 6000 times gravity for 20 minutes

c. Pour off excess once finished

6. Make up a solution of $1 \mathrm{x}$ Pkm with $20 \%$ glycerol

a. Before adding glycerol filter with syringe (or prefilter a large amount that can be used many times)

b. Mix $20 \mathrm{~mL}$ of $1 \mathrm{x}$ pkm and $5 \mathrm{~mL}$ of $70 \%$ glycerol $(25 \mathrm{~mL}$ is used assuming that the initial OD is about 0.25 , this results in an OD of about 0.02 when $1 \mathrm{~mL}$ of the final solution is added to the reactors)

7. Add the Pkm glycerol mix to the pellets

a. Add some to the first pellet and resuspend, then add that to the next and so on

b. Add any remaining Pkm glycerol mix to the combined pellets

c. Make sure that solution is well mixed, and all cells are resuspended

8. Add $1 \mathrm{~mL}$ of the final solution to cryovials and freeze in blue isopropyl slow-freeze container for at least 2 hours

a. Cryovials can be found in lab A8

APPENDIX D: Detailed Gluconobacter oxydans growth in the SixFors

1. Check all O-rings, vacuum grease, D.O. probes, and condenser

a. O-rings are used in each mettle probe fitting, fermenter mettle tops, and tops of the stir shafts (check the white stoppers on the stir shafts for proper orientation)

b. Replace any that look worn or damaged

i. If replacing the large top O-ring, make sure that high temperature vacuum grease is added

c. Before adding the D.O. probes to the fermenters check them for any damage

d. Check the water level in the condenser machine

i. Water level should be midway filled or more

2. Add the media into each fermenter

a. Pour $100 \mathrm{~mL}$ of $5 \mathrm{x}$ Pkm to each one

b. Top off with $400 \mathrm{~mL}$ of $\mathrm{npH}_{2} \mathrm{O}$

c. Mark the water level in the fermenter after the top and probes are added

3. The mettle port cap should not be used for autoclaving!

a. Use a sponge stopper to cap the solid addition port

4. Adding the D.O. probe 
a. The mettle fitting that holds it should be left loose when inserting the probe

i. Wet the O-rings or probes so that the probes can slide in more easily

b. The probe is longer than the fermenters so make sure that the tip does not touch the bottom or magnets on the stir shaft

c. Finger tighten the mettle fittings once the probe is inserted to the correct level

d. Keep the end of the D.O. probe that connects to the SixFors capped throughout the autoclave process

5. Calibrate the $\mathrm{pH}$ probe

a. Connect the $\mathrm{pH}$ probe to the SixFors reactor

b. Wash the $\mathrm{pH}$ probes with distilled water so that any remaining Broadley James salt solution is removed

c. Go through the menus for calibrations

d. After calibration the probes can be added to the fermenters

e. Don't turn the SixFors reactor off!

f. Keep the end of the $\mathrm{pH}$ probe that connects to the SixFors capped throughout the autoclave process

6. Adding the $\mathrm{pH}$ probe

a. The mettle fitting that holds it should be left loose when inserting the probe

i. Wet the O-rings so that the probes can slide in more easily

b. Finger tighten the mettle fittings once the probe is inserted to the correct level

7. Check that the air pipe is close but isn't touching the stir shaft

a. The air pip is L-shaped

b. Use the small flat head screwdriver located in one of the draws under the SixFors reactor

c. Either wrap filters in tinfoil and autoclave them with the fermenters or use new sterile filters when starting up the SixFors

i. Filters are needed to sterilize the air being pumped into each fermenter since forced air has a higher risk of potential contamination

d. Mark the water level in the fermenters

8. Check how the condenser is oriented on the vessel

a. Orent the condenser so that the tubes are facing out over the volume markings

b. Also set the clamp in the same orientation

i. This allows the fermenters to sit in the SixFors easily

9. Cover all ends of any tubes

a. This includes any tips that are open to the air and any fittings that are joined together

10. Autoclave

a. Do a 60 min liquid run

11. After autoclaving let the fermenters cool down to room temperature

a. This can be done overnight or for about 3-4 hours

i. Cover the top of the fermenters with tinfoil

1. This is done to prevent any contamination from falling onto the fermenters while they sit and cool

12. Place all of the fermenters into their designated blocks

a. Connect the $\mathrm{pH}$ and D.O. probes to their SixFors connections

13. Insert the temperature probes 
14. Connect the condenser pipes up to the SixFors

a. Check that the water valves of each fermenter are in the open position

15. Let the D.O. probes polarize 4-6 hours or overnight

a. Cover the reactors with tin foil to prevent dust from settling on them

16. Add glucose

a. Using sterile techniques add $40 \mathrm{~mL}$ of $50 \%$ glucose to the fermenters for a final glucose concentration of $40 \mathrm{~g} / \mathrm{L}$

b. Fill to the water mark with $\mathrm{npH}_{2} \mathrm{O}$

c. Replace the sponge stopper with the mettle ones using the large flat head screwdriver

17. Check that everything is oriented properly in the reactor

a. The stir magnet shaft is sitting in the white stopper at the bottom of the vessel

b. The white stopper and small O-ring at the top of the stir magnet shaft is set properly

18. Start each fermenter

a. Check that only temperature and rpm are controlled for each fermenter as you turn them on

19. Set the temperature

a. Temperature should be set at $30^{\circ} \mathrm{C}$

20. Turn the rpm on for each fermenter

a. rpm should be set to 200 for D.O. calibration

21. Turn the condenser machine on

a. Should be set at $17-18^{\circ} \mathrm{C}$ already but if not adjust the temperature

b. Calibrate the D.O. probe Adjust all air flows to 60 for each fermenter once the air tube and filter is connected and turned on

i. Let the nitrogen run for an hour or more

ii. Record this as your low reading

c. Turn the nitrogen off and turn the air on

i. Re-adjust the air flow to 60 (may have changed some with the switch)

ii. After about an hour record this as your high value

22. Adjust rpm to 600 for growth

23. Turn the computers on and start collecting data

a. Check the time on the computer and adjust if needed before collecting data

24. Inoculate the reactors

a. Take 6 frozen cryovials from the refrigerator and let them warm to room temperature

i. Suck up the culture in the cryovials with a $1 \mathrm{~mL}$ syringe and an 18-gage needle

ii. Take off the needle and replace its cap so that it can be safely deposed of

iii. Take off the tinfoil on the liquid addition tube connected to a fermenter and attach the syringe

iv. Discharge the culture fully

1. After discharge, disconnect the syringe and take in air

2. Reconnect the syringe and push air through the tube to expel all of the culture into the vessel

3. Do this once more (twice total) 
v. Do this for each fermenter but there is no need to change the needle or syringe if they don't touch anything else

b. If added at 4:00 pm, 39 hours later will be 7:00 am two days later

i. Example: Monday 4:00 pm inoculation = Wednesday 7:00-8:00 am harvest

25. Clamp each liquid port tube to close them

a. They may leak if kept unclamped

26. Take samples from the fermenters to get $\mathrm{OD}_{600}$ readings

a. Make sure that the spectrometer in lab A8 is turned on before taking samples

i. Power button is on the back

b. Use a $3 \mathrm{~mL}$ syringe to extract $1 \mathrm{~mL}$ of media

c. Place this into a small centrifuge vial

i. Found in one of the cabinets under the SixFors

ii. Grab a vial holder from lab A8 to hold all of the samples

d. Transport vials to lab A8 and take OD readings at $600 \mathrm{~nm}$

e. Dispose of the vials in the autoclave waste and wash the cuvettes with DI water

27. Re-clamp each liquid port tube after a sample is taken

28. Check the air currents every once and a while

a. They may decrease over time (filters start to fill up with debris)

29. Turn the condenser machine and air off at the wall

30. Stop each fermenter by going through the SixFors menus

a. Transfer all of the data obtained by the computer to a flash drive

31. Turn off the SixFors

32. Disassemble the fermenters Part 1

b. Disconnect the condenser hoses from each fermenter and wipe up any water that may spill out of them

c. Shut the air off at each fermenter, then disconnect the air tubes

d. Take out the temperature probes

e. Disconnect $\mathrm{pH}$ probes

f. Starting with fermenter 6 disconnect the D.O. probes

i. Use the pliers to take off the caps that connect the D.O. probes to the SixFors

ii. As you disconnect a D.O. probe remove the fermenter and shut the water valves

33. Transport the fermenters to lab A8

a. Bring the rack that holds the Broadley James salt solution and cardboard sleeves

iii. Don't forget to grab the cups with the varies probe caps

34. Pull the probes out of the fermenters and wash them

a. Wash the $\mathrm{pH}$ probe with wash water and rinse with DI water, dry with chem wipe, place in cardboard sleeve, insert into the Broadley James salt solution bottles, and wrap with parafilm

b. Wash D.O. probe with DI water, wipe down with $70 \%$ ethanol, quickly rinse with DI water, and replace the caps before storing

35. Disassemble the fermenters Part 2 
a. Unscrew all three port screws and wash with wash water and rinse with $70 \%$ ethanol and DI water

b. Remove the condenser from the top and run $70 \%$ ethanol through it, then rinse with DI water

c. Take off the top and remove all components

d. Clean everything with wash water and rinse with $70 \%$ ethanol

i. This includes the hoses

ii. Push $70 \%$ ethanol through the hose that comes out of the fermenter tops and goes right back in with no breaks by squeezing ethanol through the tips found on the bottom of the top

iii. With the other hose that comes out of the fermenter top and goes back in there is a connection that you can take apart

1. Take this apart and push $70 \%$ ethanol through with the bottle

iv. Once ethanol has been pushed through all of the tubes, including the air tube, flush them with DI water

e. Rinse everything else with $70 \%$ ethanol and then with DI water

f. Set the fermenter vessels aside and cover with parafilm

i. Measure the amount of liquid in each fermenter visually

36. Harvesting the media

a. Centrifuge at 6000 times gravity for 30 minutes

b. Clean the vessels with wash water and then rinse with $70 \%$ ethanol and DI water

37. Filter the supernatant with $0.2 \mu \mathrm{m}$, PES

a. Resuspend the pellets and discard them in the biological waste tub in the hood by the sink

b. Store the lixiviant in the refrigerator

38. Assemble the clean fermenters and place them back by the SixFors

39. Autoclave the mettle port caps and filters

40. To find the acid concentrations send out for analysis

a. Place $2 \mathrm{~mL}$ of lixiviant from each fermenter into a HPLC vial

41. If you also want a sugar analysis done refer to the directions in the corn stover procedure but don't do the dilutions 
APPENDIX E: Detailed bioleaching table of organization

\begin{tabular}{|c|c|c|c|c|c|c|c|c|}
\hline Sample \# & Vial \# & Triplicate & Time & Temperature & RPMs & $\%$ Pulp & $\left|\mathrm{FeSO}_{4}(\mathrm{~g})\right|$ & Added Acid (10 mL) \\
\hline \multirow{3}{*}{1} & 1 & $\mathrm{~A}$ & 24 & 30 & 150 & 1.5 & 0.260 & F2 Lixiviant \\
\hline & 2 & $\mathrm{~B}$ & 24 & 30 & 150 & 1.5 & 0.260 & F4 Lixiviant \\
\hline & 3 & $\mathrm{C}$ & 24 & 30 & 150 & 1.5 & 0.260 & F5 Lixiviant \\
\hline \multirow{3}{*}{2} & 4 & A & 1.5 & 30 & 150 & 1.5 & 0.260 & F2 Lixiviant \\
\hline & 5 & B & 1.5 & 30 & 150 & 1.5 & 0.260 & F4 Lixiviant \\
\hline & 6 & $\mathrm{C}$ & 1.5 & 30 & 150 & 1.5 & 0.260 & F5 Lixiviant \\
\hline \multirow{3}{*}{3} & 7 & $\mathrm{~A}$ & 6 & 30 & 150 & 1.5 & 0.260 & F2 Lixiviant \\
\hline & 8 & $\mathrm{~B}$ & 6 & 30 & 150 & 1.5 & 0.260 & F4 Lixiviant \\
\hline & 9 & $\mathrm{C}$ & 6 & 30 & 150 & 1.5 & 0.260 & F5 Lixiviant \\
\hline \multirow{3}{*}{4} & 10 & $\mathrm{~A}$ & 18 & 30 & 150 & 1.5 & 0.260 & F2 Lixiviant \\
\hline & 11 & $\mathrm{~B}$ & 18 & 30 & 150 & 1.5 & 0.260 & F4 Lixiviant \\
\hline & 12 & $\mathrm{C}$ & 18 & 30 & 150 & 1.5 & 0.260 & F5 Lixiviant \\
\hline \multirow{3}{*}{5} & 13 & $\mathrm{~A}$ & 24 & 20 & 150 & 1.5 & 0.260 & F2 Lixiviant \\
\hline & 14 & $\mathrm{~B}$ & 24 & 20 & 150 & 1.5 & 0.260 & F4 Lixiviant \\
\hline & 15 & $\mathrm{C}$ & 24 & 20 & 150 & 1.5 & 0.260 & F5 Lixiviant \\
\hline \multirow{3}{*}{6} & 16 & $\mathrm{~A}$ & 24 & 50 & 150 & 1.5 & 0.260 & F2 Lixiviant \\
\hline & 17 & $\mathrm{~B}$ & 24 & 50 & 150 & 1.5 & 0.260 & F4 Lixiviant \\
\hline & 18 & $\mathrm{C}$ & 24 & 50 & 150 & 1.5 & 0.260 & F5 Lixiviant \\
\hline \multirow{3}{*}{7} & 19 & A & 24 & 70 & 150 & 1.5 & 0.260 & F2 Lixiviant \\
\hline & 20 & B & 24 & 70 & 150 & 1.5 & 0.260 & F4 Lixiviant \\
\hline & 21 & $\mathrm{C}$ & 24 & 70 & 150 & 1.5 & 0.260 & F5 Lixiviant \\
\hline \multirow{3}{*}{8} & 22 & $\mathrm{~A}$ & 24 & 30 & 150 & 3 & 0.530 & F2 Lixiviant \\
\hline & 23 & $\mathrm{~B}$ & 24 & 30 & 150 & 3 & 0.530 & F4 Lixiviant \\
\hline & 24 & $\mathrm{C}$ & 24 & 30 & 150 & 3 & 0.530 & F5 Lixiviant \\
\hline \multirow{3}{*}{9} & 25 & A & 24 & 30 & 150 & 6 & 1.080 & F2 Lixiviant \\
\hline & 26 & $\mathrm{~B}$ & 24 & 30 & 150 & 6 & 1.080 & F4 Lixiviant \\
\hline & 27 & $\mathrm{C}$ & 24 & 30 & 150 & 6 & 1.080 & F5 Lixiviant \\
\hline \multirow{3}{*}{10} & 28 & A & 24 & 30 & 150 & 33 & 8.270 & F2 Lixiviant \\
\hline & 29 & $\mathrm{~B}$ & 24 & 30 & 150 & 33 & 8.270 & F4 Lixiviant \\
\hline & 30 & $\mathrm{C}$ & 24 & 30 & 150 & 33 & 8.270 & F5 Lixiviant \\
\hline \multirow{3}{*}{11} & 31 & $\mathrm{~A}$ & 24 & 30 & 150 & 1.5 & 0.260 & $220 \mathrm{mM}$ of Sulfuric \\
\hline & 32 & $\mathrm{~B}$ & 24 & 30 & 150 & 1.5 & 0.260 & $220 \mathrm{mM}$ of Sulfuric \\
\hline & 33 & $\mathrm{C}$ & 24 & 30 & 150 & 1.5 & 0.260 & $220 \mathrm{mM}$ of Sulfuric \\
\hline \multirow{3}{*}{12} & 34 & $\mathrm{~A}$ & 24 & 30 & 150 & 1.5 & 0.260 & Sulfuric with pH of 2.15 \\
\hline & 35 & $\mathrm{~B}$ & 24 & 30 & 150 & 1.5 & 0.260 & Sulfuric with pH of 2.15 \\
\hline & 36 & $\mathrm{C}$ & 24 & 30 & 150 & 1.5 & 0.260 & Sulfuric with pH of 2.15 \\
\hline \multirow{3}{*}{13} & 37 & $\mathrm{~A}$ & 24 & 30 & 150 & 1.5 & 0.260 & $220 \mathrm{mM}$ of Gluconic \\
\hline & 38 & $\mathrm{~B}$ & 24 & 30 & 150 & 1.5 & 0.260 & $220 \mathrm{mM}$ of Gluconic \\
\hline & 39 & $\mathrm{C}$ & 24 & 30 & 150 & 1.5 & 0.260 & $220 \mathrm{mM}$ of Gluconic \\
\hline \multirow{3}{*}{14} & 40 & $\mathrm{~A}$ & 24 & 30 & 150 & 1.5 & 0.450 & F2 Lixiviant \\
\hline & 41 & $\mathrm{~B}$ & 24 & 30 & 150 & 1.5 & 0.450 & F4 Lixiviant \\
\hline & 42 & $\mathrm{C}$ & 24 & 30 & 150 & 1.5 & 0.450 & F5 Lixiviant \\
\hline \multirow{3}{*}{15} & 43 & A & 24 & 30 & 150 & 18 & 3.690 & F2 Lixiviant \\
\hline & 44 & $\mathrm{~B}$ & 24 & 30 & 150 & 18 & 3.690 & F4 Lixiviant \\
\hline & 45 & $\mathrm{C}$ & 24 & 30 & 150 & 18 & 3.690 & F5 Lixiviant \\
\hline
\end{tabular}


APPENDIX F: Detailed bioleaching procedure and analysis

1. Retrieve $50 \mathrm{~mL}$ conical vials to perform leaching experiments

a. Label each vial

b. Do each experiment in triplicate

c. Weigh the empty conical vial in lab B7 with the fancy scale

2. Add $\mathrm{LiCoO}_{2}$ to the conical vial

a. Look to data tables for the amount required

3. Add $\mathrm{FeSO}_{4}$ to vials

a. Look to the data tables for the amount required

4. Add $10 \mathrm{~mL}$ of the chosen bio-lixiviant or acid to each conical vial

5. Incubate the vials according to the data tables

6. After incubation weigh the vials to get the total mass

7. Centrifuge for $10 \mathrm{~min}$ at 10,000 times gravity $(\sim 9000 \mathrm{rpm})$

a. Setting the centrifuge to $6^{\circ} \mathrm{C}$ seems to help the pellets set and not start to dissolve once the centrifuge stops

8. Filter supernatant through $0.2 \mu \mathrm{m}$ syringe filters

a. Filter about $5 \mathrm{~mL}$ into $15 \mathrm{~mL}$ conical vials and add $50 \mu \mathrm{L}$ of Nitric acid

i. This creates a $1 \%$ solution of Nitric acid for ICP analysis

b. Filter about $1 \mathrm{~mL}$ into small centrifuge tubes and transport these over to EIL to be tested in the TXRF spectrometer

c. Filter the remainder into a glass vial for $\mathrm{pH}$ readings

i. Calibrate the $\mathrm{pH}$ probe before you start to take readings

9. Dispose of the leftover spent solution

a. Label a $1 \mathrm{~L}$ glass orange toped bottle "Spent Lixiviant" and add the any leftover solution to it along with the amount used for the $\mathrm{pH}$ readings

10. Follow the TXRF directions provided to run the samples

a. In this case disposable disks were used so that the cleaning time could be eliminated

i. The disposable disks are acrylic, and more may need to be ordered depending on how many are left

ii. The acrylic disks have a thin film of plastic on each side that needs to be removed before use

iii. These disks are acrylic instead of quartz so when drying the sample only heat them to $50^{\circ} \mathrm{C}$

b. The samples were diluted 1 to 50 before they were run

i. The final volume was $100 \mu \mathrm{L}$ which contained $88 \mu \mathrm{L}$ of $0.2 \%$ PVA, 10 $\mu \mathrm{L}$ of a Selenium standard, and $2 \mu \mathrm{L}$ of your sample

c. When placing the disks into the TXRF orient them so that the sample is facing into the TXRF and the label that you placed on them is facing you

i. You should be able to read the label

d. The disks were run for 250 seconds when finding a good dilution but for the final analysis they were run for 1000 seconds 


\section{REFERENCES}

1. Binnemans, K., et al., 2013. Recycling of rare earths: a critical review. J. Clean. Prod. 51, 1$\underline{22 .}$

2. Brierley, C. L.; Brierley, J. A., Progress in bioleaching: part B: applications of microbial processes by the minerals industries. Applied microbiology and biotechnology 2013, 97 (17), 7543-7552.

3. Crain-Zamora, M.; D.W. Reed. 2017. Organic acid production from food wastes using Gluconobacter oxydans: A possible source of cheaper lixiviants for leaching REE from end-of-life products. Science Undergraduate Laboratory Internship Program (2017).

4. De Michelis, I., Ferella, F., Varelli, E.F., Vegliò, F., 2011. Treatment of exhaust fluorescent lamps to recover yttrium: experimental and process analyses. Waste Manag. 31 (12), 2559-2568.

5. Fisher, Jacob L. Bench-Scale Model Ready for Large Scale Implementation: Rare Earth Bioleaching Using an Economical Carbon Source. Idaho National Laboratory, 2017, pp. $1-25$.

6. Pikovskaya, R., 1948. Mobilization of phosphorus in soil in connection with vital activity of some microbial species. Mikrobiologiya 17, 362-370.

7. Prust, Christina, et al. "Complete Genome Sequence of the Acetic Acid Bacterium Gluconobacter oxydans." Nature Biotechnology, vol. 23, no. 2, 2005, pp. 195-200.

8. Reed, D. W.; Fujita, Y.; Daubaras, D. L.; Jiao, Y.; Thompson, V. S., 2016. Bioleaching of rare earth elements from waste phosphors and cracking catalysts. Hydrometallurgy, 166, 3440. 
9. Lister, Tedd \& Reed, David \& Klaehn, John \& Diaz Aldana, Luis \& McNally, Joshua. Provisional patent application for Attorney Docket 2939-14882US (BA-1087). Methods of Recovering Active Mateirals From Rechargeable Batteries, And Related Apparatuses.

10. Thompson, Vicki \& Gupta, Mayank \& Jin, Hongyue \& Vahidi, Ehsan \& Yim, Matthew \& A Jindra, Michael \& Nguyen, Van \& Fujita, Yoshiko \& Sutherland, John \& Jiao, Yongqin \& Reed, David. (2017). Techno-economic and Life Cycle Analysis for Bioleaching Rare Earth Elements from Waste Materials. ACS Sustainable Chemistry \& Engineering. 6.10.1021/acssuschemeng.7b02771. 